\title{
Performance Measurement and Management System - Inter Company Case Study Approach - Tamilnadu, India
}

\author{
S.Venkatesh , Dr.S.Ramachandran \\ Research Scholar, BHARATH University, Chennai , INDIA \\ ( Research Supervisor -, Director-BHARATH School of Business , BHARATH University , Chennai, INDIA )
}

\begin{abstract}
The field of performance measurement and management (PMM) is well filled with frameworks, models and guidelines addressing what to measure and how to design a performance measurement system (PMS). However, what has been less examined so far is how to ensure that PM evolve in tandem with their environments. Further, the few approaches available today are prescriptive and outlines how or what practitioners should do in order to manage change in their PM. Thus, a gap exists in understanding how organisations manage change in their PM in practice. Thus, the purpose of this paper is to outline and compare the approaches of three case companies for managing PM change. In order to fulfil the purpose of the paper, the data presented has been collected through the deployment of case studies. The choice of case studies as means for data collection stems from the possibility of an in-depth and holistic examination of the formulated phenomenon. All three case companies belong to the same company-group that operates within the transportation industry. The industrial footprint of the company is global with operations and sales spread out over the world. The findings suggest that all three companies have processes in place for managing change in $P M$. However, the approaches differ in design and context. Furthermore, employee involvement seemed to be the biggest challenge for all three companies.This paper makes a contribution both through describing how three companies manage PM change and through elaborating on the underlying factors affecting functionality.

Keywords: Performance measurement, Performance measurement systems, Performance management
\end{abstract}

\section{Introduction}

Performance measures (PM) are used in organisations for a wide array of reasons: to gauge performance (Slack et al., 2004), direct behaviour and improve motivation (Spitzer, 2007), continuously improve processes (Cross and Lynch, 1992), enhance productivity (Bernolak, 1997), identify areas of attention, improve communication, increase accountability (Waggoner et al., 1999), implement strategy (Kaplan and Norton, 2001), support goal achievement (Tapinos et al., 2005) and provide information on strategy implementation (Neely, 1999). Regardless of the reason to why PM are deployed, it is widely recognised in the literature that PM need to be aligned with the strategic priorities, as well as the internal and external environments of the organisation (Neely et al., 1996; Bourne et al., 2000; Bititci et al., 2001; McAdam and Bailie, 2002; Hass et al., 2005; Lima et al., 2009). However, as these strategies and business environments are dynamic in nature (Simons, 1995), organisations need to ensure that they are capable of managing change in their PM (Bititci et al., 2000; Kennerley et al., 2003). Sticking to your PM for too long has been described by Likierman (2009) as one of the five traps of performance measurement.

The field of performance measurement and management (PMM) is well filled with frameworks, models and guidelines addressing what to measure and how to design a performance measurement system (PMS) (Paranjape et al., 2006), most notably the Balanced Scorecard (Kaplan and Norton, 1992). However, what has been less examined so far, is how to ensure that PM evolve in tandem with their environments (Kennerley and Neely 2003). Barrows and Neely (2012) argue that contemporary methods do not adequately address the challenges associated with managing performance in an increasingly turbulent business environment. Further, the few approaches available today are prescriptive and outlines how or what practitioners should do in order to manage change in their PM. None of the approaches take a descriptive stance and outlines how organisations take on the challenge today. Thus, a gap exists in understanding how organisations manage change in their PM in practice (Bourne, 2008). This gap is further amplified by the fact that only a few organisations have procedures in place to manage the change of their PM (Neely, 1999; Bititci et al., 2002).

With this background in mind, the purpose of this paper is to outline and compare the approaches of three case companies for managing PM change. The motive for the paper is to bridge the knowledge gap, by contributing to the understanding of how PM change is managed in practice and assist in the development of adequate theoretical models by shedding light on the problems encountered in practice. The paper is divided into six sections. The following section presents the theoretical background. The third section outlines the methodological approach and presents the case studies. This is followed by a presentation of the empirical findings. The succeeding section then contrasts the empirical and theoretical findings through a cross-case 
analysis. The sixth section summarises the findings and discusses the necessities of a future research agenda, highlights the contributions and underlines the limitations of the conducted research.

\section{Theoretical Background}

Even though change in PM, in contrast to design of PM, remains an under-researched area, several academics have addressed the topic over the last decade. The progress made so far is presented in this section. Neely et al. (2002b) argue that a process needs to be in place in order to ensure that temporary PM are abolished and indispensable PM are fine-tuned continuously. For this purpose, an audit with 10 questions is provided within their Performance Prism framework. Kennerley and Neely $(2002$; 2003) list a process that that reviews, modifies and deploys PM as one of four critical factors in their framework for keeping PMS up to date. Neely et al. (2002a) argue that PMS are often allowed to expand to the extent that they become unmanageable and thus a PM review process needs to be in place. It is underlined that the understanding of the process evolves over time. Medori and Steeple (2000) concurs and lists periodic maintenance as the last step in their framework for auditing and enhancing PMS. They argue that a periodical PMS review is required as PM relevant at one particular moment in time may become redundant at another point. Meekings (2005) has developed a set of requirements for a functional review process, including a defined structure, connection throughout the organisation, deliver value and PM change management. Kaplan and Norton $(2005 ; 2008)$ argue that two parameters are needed for managing PM change, a clearly defined and recurring process, and the establishment of an entity responsible for its management and success. Bourne et al. (2000) support and develop earlier findings by arguing that four processes need to be in place to review targets of current measures, review current measures, develop new measures and to challenge the strategy. Bititci et al. (2000) highlights in their dynamics PMS model that a PM review mechanism is needed which uses the performance information provided by the internal and external monitors. Further, a deployment system is also required in order to revise objectives and priorities to business units, processes, and activities using performance measures are required.

Besides the review process, the role of organisational culture is emphasised in the literature. Waggoner et al. (1999) underline the impact that organisational culture can have on PMS evolution. They argue that a culture, which discourages risk taking and innovation, can block steps that are essential for successfully changing a

PMS. Kennerley and Neely (2002; 2003) concur and underline the need of a culture within the organisation that ensures that the value of measurement, and the importance of maintaining relevant and appropriate PM are appreciated (Table 1). Salloum and Wiktorsson (2011) argue that in order to realise a dynamic PMS, a culture is needed that encourages organisational involvement, openness, information sharing, and resource availability. Farris et al. (2011) identified two critical factors for a supportive organisational culture in their investigation of the PM review process: employee empowerment (including focus on teamwork, ownership of problems, participation and entrepreneurship) and a focus on continuous improvement.

Table 1: Barriers and enablers for culture (Kennerley et al., 2003

\begin{tabular}{|l|l|l|}
\hline S.No & Cultural Barriers to Measures Evolution & Cultural Enablers of Measures Evolution \\
\hline 1 & $\begin{array}{l}\text { Management inertia towards measures due to other } \\
\text { priorities }\end{array}$ & Senior management sponsorship \\
\hline 2 & $\begin{array}{l}\text { Ad hoc approach to measuremen } \\
\text { communication of multidimensional } \\
\text { performance to staff }\end{array}$ & Open and honest application of measures \\
\hline 3 & Measures not aligned to strateg & No blame / No game environment \\
\hline 5 & Actions not aligned to measure & $\begin{array}{l}\text { Lack of management concern for non-investor } \\
\text { stakeholders }\end{array}$ \\
\hline
\end{tabular}

Further, the role of management is another factor that is recurring in the literature. Waggoner et al. (1999) highlight the impact and importance of management from several perspectives; top-level support, internal influence, process, and transformational issues. Spitzer (2007) concurs and underlines that PM change has to be driven by the leader, from the top of the organisation. Kennerley and Neely $(2002 ; 2003)$ argue that management commitment and training are two factors needed in order to facilitate PMS evolution. Further, Kennerley et al. (2003) highlight the risk of management inertia towards PM as a barrier for evolution. In an empirical study conducted at a large manufacturing unit, it was concluded that management commitment, style, competence, and politics are factors that have a high impact on the dynamic abilities of a PMS (Salloum and Wiktorsson, 2011). Kennerley and Neely $(2002 ; 2003)$ further stress the availability of flexible information technology to enable the collection, analysis and reporting of appropriate data as crucial for the evolution of a PMS (Table 2). Wettstein and Kueng (2002) argue that IT capabilities are pivotal for initiating and accelerating PMS change. They argue that IT consistently offers new opportunities to automate processes, enhance communication, and develop data analysis sequences. In the integrated model forwarded by Bititci et al. (2000), 
the required capabilities for dynamic PMS are divided into two categories, framework capabilities and IT platform capabilities. For the IT platform, four requirements were identified:

1. Able to provide an executive information system.

2. Capable of accommodating and incorporating all the elements of the framework.

3. Integrated within the existing business systems.

4. Capable of handling simple rules, such as alarms and warning signals, to facilitate performance management.

Table 2: Barriers and enablers for systems (Kennerley et al., 2003

\begin{tabular}{|l|l|l|}
\hline S.No & System Barriers to Measures Evolution & System Enablers to Measures Evolution \\
\hline 1 & Inflexible legacy system & Investment in IT hardware and software \\
\hline 2 & Poorly or partially implemented ERP system & Data mining / warehousing capability \\
\hline 3 & $\begin{array}{l}\text { Difficult to tailor 'off-the-shelf' performance } \\
\text { reporting software }\end{array}$ & Readily customisable information systems \\
\hline 4 & Poor use of graphical representation & Internal systems development and adaptation capability \\
\hline
\end{tabular}

\subsection{Synthesising the theoretical background}

The advancements within the PMM field regarding PM change can be perceived through two perspectives, structural and behavioural. The structural perspective stresses the need for processes, mechanisms and procedures for managing PM change. Furthermore, within the structural perspective, emphasis is put on the capabilities and flexibility of the IT-systems. The need to have a process/mechanism/procedure in place for continuously reviewing and changing PM is a feature that the researchers in general highlight as important.

However, how the process/mechanism ought to be designed and function is not agreed upon. The previous research ranges from only mentioning the need for a review process (Medori and Steeple, 2000) to literature studies (Waggoner et al., 1999) and models for how manage PM change (Bititci et al., 2000). Some frameworks (Neely et al., 2002a; Bourne et al., 2000) elaborate on the responsibilities of such a process but provide little direction on how it might take shape in practice. Others (Kennerley and Neely, 2002; Neely et al, 2002a) debate and argue more on the design by outlining important factors to consider, questionnaires to deploy, and management tools to implement. From a behavioural perspective, the role of senior management, culture and employee involvement/empowerment are all underlined as important factors (Waggoner et al., 1999; Kennerley and Neely, 2002; Kennerley and Neely, 2003; Salloum and Wiktorsson, 2011; Farris et al., 2011).

Previous research generally neglects the context that PM operates in and research within manufacturing organisations is missing. PM are deployed across organisations, from executive management teams to shopfloor teams. The further down in the organisation you look, the more PM you will find in need of review. Hence, any functional review process to work in practice needs to take a wide perspective and incorporate the whole organisation. The approaches presented in the theoretical background appear to take a managerial rather than an organisational perspective to the review of PM. Moreover, PM works in open production systems, heavily influenced by their temporal, cultural, and social contexts. In practice, PM are surrounded by a considerable amount of contingency (Tangen, 2005).

Thus, the final applicability and functionality can depend upon a number of factors beyond the actual review process. In regards to the purpose of this paper the theoretical foundation is limited. None of the previous publications neither illustrate how PM change is managed in practice nor takes an organisation-wide perspective. Hence, no research has been found that can be contrasted with the empirics presented in this paper. Instead, the empirics will be put in juxtaposition to the characteristics and advocacies of the theoretical background and discussed from the basis of commonalities and divergences.

\section{Method}

In order to fulfil the purpose of the paper, the data presented has been collected through the deployment of case studies (Table 3). The choice of case studies as means for data collection stems from the possibility of an in-depth and holistic examination of the formulated phenomenon (Merriam, 1994; Bell, 1999). The unit of analysis (Yin, 1994) in all three cases has been the way of working for managing change in PM. Three factors have guided the selection of case companies; the existing procedures for handling PM change at each case company, the knowledge about the company practices that the researcher could obtain before the case execution and the possibility to get unrestricted access to interviewees and databases.

The theoretical findings presented in Section 2 played several important roles in the research. It has helped to develop sharper and more profound objectives and questions in line with the arguments by Yin (1994). Further, it has also served as an initial guide to the case study design and data collection and as a part of the iterative process of data collection and analysis (Eisenhardt, 1989). The interview questionnaires used within the interview studies have been based on the literature presented in the theoretical background. The interview 
questionnaires consisted of three parts. The initial part focused on the design and features of the deployed PMS. The second part revolved around how the case company managed PM change whilst the concluding part focused on the factors and mechanisms that, in the perception of the interviewee, affected the management of PM change. Each case study was analysed in isolation through of data reduction, theme clustering and patternmatching (Miles and Huberman, 1994; Yin, 1994; Merriam 1994) before the cross-case analysis. The cross-case analysis was executed in line with what is advocated by Eisenhardt (1989) (Table 3).

Validity and reliability are highlighted by Yin (1994) as important research quality factors to consider. In order to ensure validity, the research conducted has been structured in a logical flow with problem statement, current state of the art and empirical investigations. The end-result describes how the studied phenomenon acts in real organisational settings. Further, representative case companies and triangulation between data collection components have been after sought (Table 3). Considerations in regards to the validity and reliability have to be made in the case study design phase as it deals to a great extent with the choice of case studies/companies. By collecting data from several companies the risk of conducting research in an exceptional and non-generalisable context is mitigated. Further, Yin (1994), argues that the concept of analytical generalisation is useful for establishing validity. Analytical generalisation dictates that the concluding research findings ought to be juxtaposed against the existing base of theory. The comparison will underline the gap between the research findings and the existing theory and highlight, depending on the extent of the gap, if more research is needed. Throughout this paper, the theoretical findings have been compared to their empirical dittos.

Table 3: Deployed case study methodology

\begin{tabular}{|c|c|c|c|}
\hline & Case Company $1 \mathrm{CC} 1$ & Case Company $2 \mathrm{CC} 2$ & Case Company 3 CC3 \\
\hline Employee Size & 800 & 1000 & 1100 \\
\hline $\begin{array}{l}\text { Geographical } \\
\text { Location }\end{array}$ & Chennai & Coimbatore & Madurai \\
\hline Business Area & $\begin{array}{l}\text { Heavy } \\
\text { automotives }\end{array}$ & Complex components & Heavy Machines \\
\hline $\begin{array}{l}\text { Number } \quad \text { of } \\
\text { Interviews }\end{array}$ & $\begin{array}{l}20 \text { interviews (from five } \\
\text { organisational levels) }\end{array}$ & $\begin{array}{l}19 \text { interviews (from five organisational } \\
\text { levels) }\end{array}$ & $\begin{array}{l}21 \text { Interviews (from six } \\
\text { organisational levels) }\end{array}$ \\
\hline Interviewees & $\begin{array}{l}\text { Site manager, } \\
\text { manager, finance } \begin{array}{r}\text { production } \\
\text { manager, }\end{array} \\
\text { production engineering manager, } \\
\text { logistics manager \& quality } \\
\text { manager. Six first-line managers. } \\
\text { Six team leaders and two } \\
\text { assemblers. }\end{array}$ & $\begin{array}{l}\text { Overall production manager, } \\
\text { production function managers, } \\
\text { second-line managers, } 6 \text { first-line } \\
\text { managers, } 3 \text { team-leaders, } 3 \text { assemblers }\end{array}$ & $\begin{array}{l}\text { Site manager, production } \\
\text { manager, quality manager, } \\
\text { logistics manager, finance } \\
\text { manager, HR manager, } \\
\text { financial controller, logistics } \\
\text { engineer, HR-partner, } 6 \text { first- } \\
\text { line managers, } 2 \text { second-line } \\
\text { managers, } 2 \text { team-leaders, } 2 \\
\text { operators. }\end{array}$ \\
\hline Interview Durations & 7-51 minutes per interview & 4-58 minutes per interview & 5-48 minutes per interview \\
\hline Interview Material & $\begin{array}{l}\text { Transcribed and validated by } \\
\text { interviewees }\end{array}$ & $\begin{array}{l}\text { Transcribed and validated by } \\
\text { interviewees }\end{array}$ & $\begin{array}{l}\text { Transcribed and validated by } \\
\text { interviewees }\end{array}$ \\
\hline $\begin{array}{l}\text { Within case data } \\
\text { analysis }\end{array}$ & $\begin{array}{l}\text { Data reduction, clustering, } \\
\text { pattern-matching }\end{array}$ & $\begin{array}{l}\text { Data reduction, clustering, pattern- } \\
\text { matching }\end{array}$ & $\begin{array}{l}\text { Data reduction, clustering, } \\
\text { pattern-matching }\end{array}$ \\
\hline Validity & $\begin{array}{l}\text { Triangulation, representative case } \\
\text { study, analytical generalisation }\end{array}$ & $\begin{array}{l}\text { Triangulation, representative case } \\
\text { study, analytical generalisation }\end{array}$ & $\begin{array}{lr}\text { Triangulation, representative } \\
\text { case study, } \\
\text { generalisation }\end{array}$ \\
\hline Reliability & $\begin{array}{l}\text { Choice of case study/company, } \\
\text { establishment of a case study } \\
\text { database }\end{array}$ & $\begin{array}{l}\text { Choice of case study/company, } \\
\text { establishment of a case study database }\end{array}$ & $\begin{array}{l}\text { Choice of case study/company, } \\
\text { establishment of a case study } \\
\text { database }\end{array}$ \\
\hline
\end{tabular}

IV. Findings

Table 4 gives an overall outline of the findings made in each case study. The findings suggest that all three companies have approaches in place for managing change in PM. However, the approaches differ in design, execution and context. Each approach is presented in the sections below from two aspects, structural and behavioural. The structural aspect focuses on how the case companies report that they ought and want to work with PM change. The behavioural aspect focuses in contrast on how the intended ways of working have 
unfolded. The distinction between the structural and behavioural sides provides a useful contrast of how the case companies want to work vis-à-vis how they actually work.

Table 4: Findings per case company summarized

\begin{tabular}{|c|c|c|c|}
\hline & CC1 & $\mathrm{CC2}$ & CC3 \\
\hline Type of approach & $\begin{array}{l}\text { One process with two loops } \\
\text { (deployment and } \\
\text { agreement/feedback) }\end{array}$ & $\begin{array}{l}\text { Two processes: business plan } \\
\text { (BP) and operational } \\
\text { development (OD) }\end{array}$ & $\begin{array}{l}\text { Unstructured } \\
\text { meetings }\end{array}$ \\
\hline $\begin{array}{l}\text { Ownership and facilitation of } \\
\text { approach }\end{array}$ & $\begin{array}{l}\text { Site manager owns the process. } \\
\text { Facilitated by the production } \\
\text { system exper }\end{array}$ & $\begin{array}{l}\text { CEO owns both processes. The } \\
\text { OD process is facilitated by } \\
\text { internal consultants }\end{array}$ & $\begin{array}{l}\text { No owner \& no } \\
\text { facilitator }\end{array}$ \\
\hline $\begin{array}{l}\text { Frequency of approach } \\
\text { execution }\end{array}$ & $\begin{array}{l}\text { Twice a year: June \& December. } \\
\text { No alterations in between }\end{array}$ & $\begin{array}{l}\text { BP: Yearly (autumn). OD: } \\
\text { Every } 6 \text { months. No alterations } \\
\text { in between }\end{array}$ & $\begin{array}{l}\text { Yearly (each } \\
\text { autumn). Alterations } \\
\text { in between depending } \\
\text { on function. }\end{array}$ \\
\hline $\begin{array}{l}\text { Time to execute the } \\
\text { approach } \\
\text { Defined and documented } \\
\text { approach }\end{array}$ & $\begin{array}{l}\text { 2-3 weeks } \\
\text { Defined and documented }\end{array}$ & $\begin{array}{l}\text { BP: 1-5 months. OD: 1-3 weeks } \\
\text { BP: defined and vaguely } \\
\text { documented OD: defined and } \\
\text { documented }\end{array}$ & $\begin{array}{l}\text { Uncertain. Around 3- } \\
4 \text { months } \\
\text { Not defined nor } \\
\text { documented }\end{array}$ \\
\hline $\begin{array}{l}\text { Factors affecting decision- } \\
\text { making }\end{array}$ & $\begin{array}{l}\text { Current performance, } \\
\text { requirements from above, } \\
\text { organisational politics, business } \\
\text { environment, appropriateness of } \\
\text { current PM }\end{array}$ & $\begin{array}{l}\text { BP: Review of strategy, current } \\
\text { performance, internal and } \\
\text { external environments. OD: } \\
\text { Strategic dialogue, one mutual } \\
\text { focus }\end{array}$ & $\begin{array}{l}\text { Requirements from } \\
\text { HQ, strategic targets, } \\
\text { current performance, } \\
\text { market demand, } \\
\text { appropriateness of } \\
\text { current PM }\end{array}$ \\
\hline Organisational involvement & Down to first-line managers & $\begin{array}{l}\text { BP: Employee involvement } \\
\text { fragmented. OD: all employees } \\
\text { involved }\end{array}$ & $\begin{array}{l}\text { Organisational } \\
\text { involvement limited } \\
\text { and fragmented }\end{array}$ \\
\hline Top-management support & $\begin{array}{l}\text { Supportive according to } \\
\text { interviews }\end{array}$ & $\begin{array}{l}\text { Supportive for both according } \\
\text { to interviews, OD reduced due } \\
\text { to prioritisation }\end{array}$ & $\begin{array}{l}\text { Supportive according } \\
\text { to interviews }\end{array}$ \\
\hline IT-infrastructure & $\begin{array}{l}\text { IT-systems fragmented after } \\
\text { function and inflexible. High } \\
\text { level of manual impositions } \\
\text { through Excel }\end{array}$ & $\begin{array}{l}\text { IT-systems limited and } \\
\text { inflexible to extraction of data. } \\
\text { Data quality doubted at some } \\
\text { organisational levels. }\end{array}$ & $\begin{array}{l}\text { Newly implemented } \\
\text { and integrated IT- } \\
\text { system. Problems } \\
\text { with extracting data } \\
\text { and developing } \\
\text { competence. }\end{array}$ \\
\hline Level of beneficial culture & $\begin{array}{l}\text { Hierarchical culture, hard to get } \\
\text { wide involvement }\end{array}$ & $\begin{array}{l}\text { Blame-game culture, } \\
\text { characterised by reactivity }\end{array}$ & $\begin{array}{l}\text { Reporting-culture, } \\
\text { measures decided } \\
\text { from above }\end{array}$ \\
\hline
\end{tabular}

\subsection{Case company 1 - The single process approach}

\subsubsection{Structural aspect}

Management system documentation and management interview results revealed that CC1 deployed a process labelled the KPI review. Interview responses from managers across the organisation exhibited that the process was based on a set of meetings initiated and closed by the top-management team. The inputs to the first meeting of the process are outlined in Table 4. Once the top-management finished their review meeting, the function management did the same exercise with the above hierarchy's (top-management) output as input. This interlinked chain of meetings was meant to continue down to the production teams in order to create alignment in the goal and PM review. Once all the review meetings have been executed a set of meetings referred to by the top-management interviewees as the agreement/feedback meetings were initiated. The purpose of these meetings was to foster consensus of the goals and PM for the coming year and was held between members of two hierarchical levels. The KPI review was accomplished once the top-management team held the last agreement/feedback meeting. The top-management team has the power to either accept the proposed PM or ask for refinements. However, during the interviews these managers underlined that even though the general manager was the owner of the process the local production system expert facilitated it. The role played by the expert was hailed by several management interviewees. One first-line manager explained that the expert was instrumental to him in getting the work done. Moreover, the interview results strongly advise that the review 
process was an established way of working at CC1 as 16 of the 20 interviewees acknowledged it. It is notably however that the four employees not recognising it came from the lower levels of the organisation. In order to enhance the communication and promote the use of PM, a payback tracker was publicly accessible at the intranet. The tracker communicated the financial effects of the PM to the organisation. Moreover, all PM were connected throughout the hierarchical levels of the organisation through the use of publicly available KPI-trees (Figure 1). The general manager explained: “...And then we do have these KPI-trees that show how everything is related throughout the organisation... I think that they [the KPI-trees] can play an important role in explaining that yes it [the measures] matters".

\section{Figure 1: Example of one measurement tree for the cost, delivery and quality PM at a department.}

\subsubsection{Behavioural aspect}

Even though interview results, especially from the top-management team, made it explicit that the intention was to involve everyone, the process was never deployed on a team level in production. One team-leader elaborated when asked how he though his team felt about working with PM: "I do not think they care...painting is pretty much all that they are interested in that... how can I say it...their main goal is the paint and to keep painting. So that is pretty much all that they are worried about..."

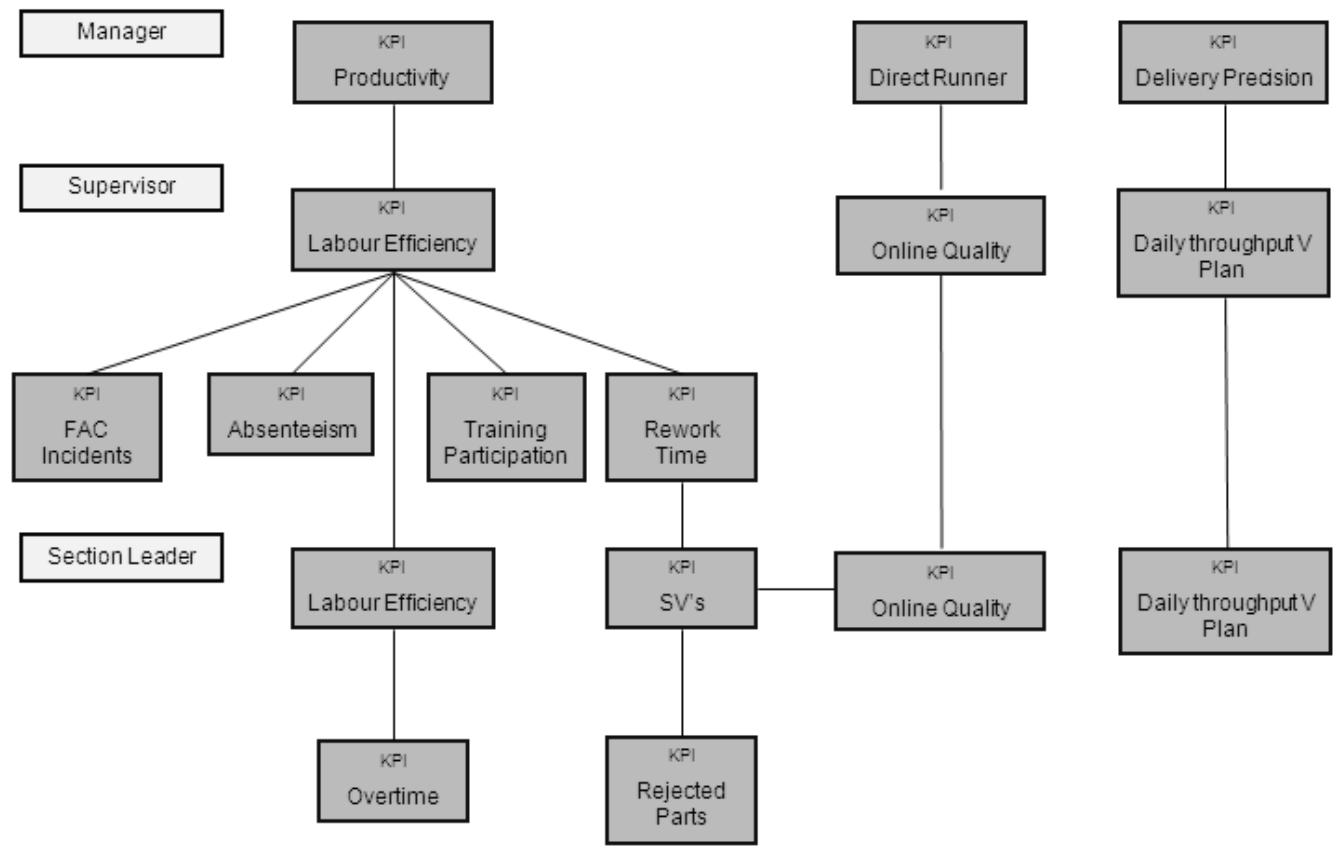

The interviewees for the top-management team were united in their view that they had not reached out fully and had a contribution to make in order to engage the whole organisation. The general manager explained that an attempt had been made to involve the teams but it was deferred as many others things came up that needed to be dealt with. The general manager described the attempt as "half-hearted". However, all six top-management interviewees still believed that the KPI review was important and supported it. One of the managers argued that the attempt failed due to the lack of management understanding regarding how to make the organisation to want to get involved. The consequences of not involving the masses in the KPI review were believed to be negative and were best expressed by the production engineering manager who argued that the involvement of the teams was crucial for the ability of the whole organisation to get something worthwhile out of the PM. Further, another contributing factor to the lack of involvement was the culture of the organisation. The production manager argued: " Here at this plant, to engage your employees equals to inform them and nothing else. No dialogue or feedback exists. You must always control that things are getting done. This is fundamentally wrong and in order to redeem this we must change the culture...this journey starts with us, the top-management team".

When asked about the culture and its impact on the PM, several managers highlighted the negative behavioural effect that the PM ownership structure had. The quality manager argued that the ownership needed to be driven down beyond the team-leaders in order to trigger involvement. Those thoughts got support by recently promoted team-leaders that expressed that their acquired PM responsibilities made them get involved. Further, the organisation did not offer any PM training to the production teams. This education was given once an operator/assembler became a team-leader. The team-leaders highlighted that the education was important for their understanding of the PM. Moreover, direct observations and interview results indicate that that CC1 had problems with their inflexible and disintegrated IT-systems. All five top-management interviewees underlined that the IT-system was inflexible in regards to what they wanted to measure. High levels of manual impositions 
for collecting and compiling data encroached on the time for analysis, limited the measurement scope and amplified the risk for human errors. The general manager explained that it sometimes felt like a project to just start measuring a new PM.

\subsection{Case company 2 - The dual process approach}

PM process documentation and interview responses exhibit that $\mathrm{CC} 2$ deployed two processes for managing PM change. The first process, labelled at $\mathrm{CC} 2$ as the business plan and goal steering process (BP\&GS) adopted a top-down approach and was confined to all the main strategic and operational PM. In converse, the second process, named the operational development process (OD) was designed as a bottom-up approach with focus on a single strategic goal.

\subsubsection{Structural aspect}

Analysis of management system guidelines and interview responses from across $\mathrm{CC} 2$ revealed that the first review process adopted a top-down approach and consisted of two loops, a business planning (BP) loop and a goal steering (GS) loop (Figure 2). According to management interviewees and documentation obtained from the intranet, the purpose of the BP loop was to ensure that the strategy of the organisation had been reviewed whilst the GS loop aligned the PM scorecards across the organisation with the reviewed strategy. Once the topmanagement team had finished their BP loop and updated the strategic material and main PM, the objectives and PM of the organisation were reviewed through the GS loop. The BP loop was thus the first process step and was confined, participation wise, to the top-management. Process material and interview responses exhibit that the GS loop was executed in a chronological fashion with output of higher hierarchical levels serving as input for the lower dittos. Moreover, the output was meant to become more specific and detailed the further down the GS loop was drilled (Figure 2). At, first-line management level specific actions were meant to be assigned to the PM and goals through the development of local business plans. The GS loop was concluded once the lowest levels of $\mathrm{CC} 1$ had reviewed and updated their PM and goals for the coming year.

Figure 2: The OD process. The process steps are highlighted in rectangles and the outputs in spheres.

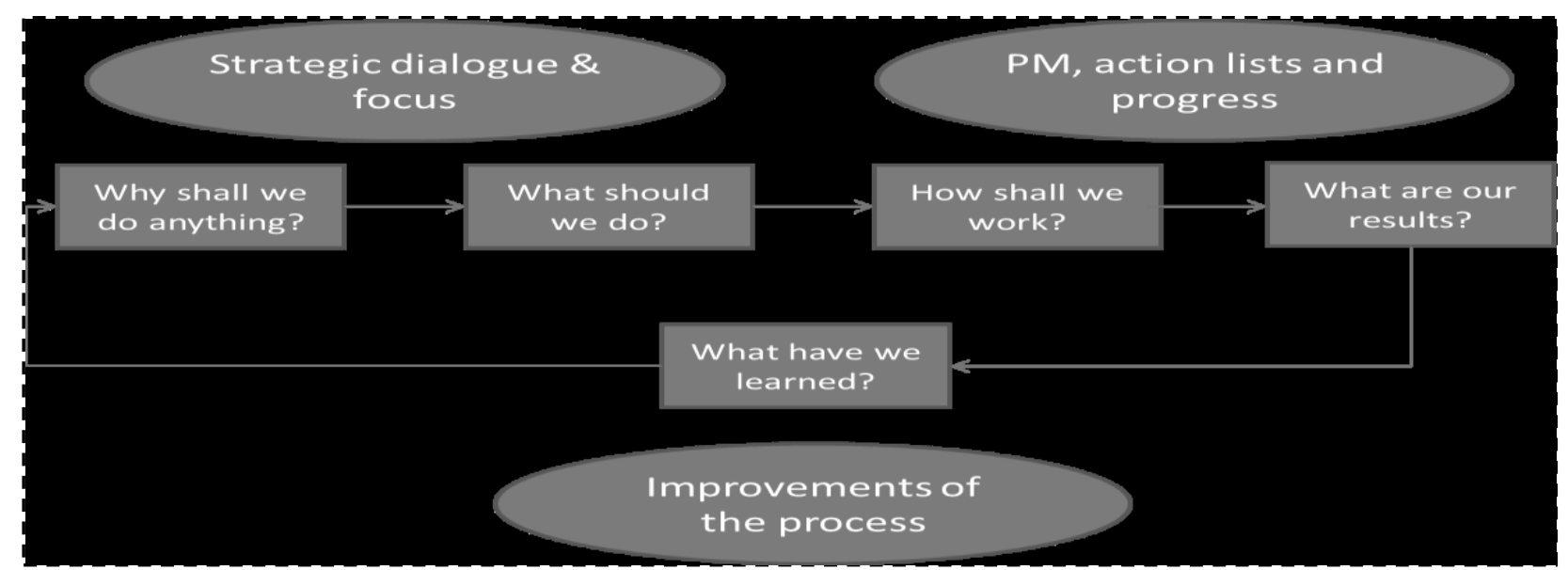

\subsubsection{Behavioural aspect}

It was underlined by several interviewees that the BP\&GS process did not work as intended, some firstline managers admitted that this was the first time in several years that they got any input from their managers. Others acknowledged that they received their input only after they had finished reviewing their PM and assignment of actions. The first-line managers that received input perceived it to be problematic that the upper management absorbed much time and thus reduced the time left for them. One of top-managers acknowledged the problem: "The further down you come the organisation the less time they have and I think that is generally speaking...we need to get better here that thing is clear...considering the vast change in activities that this work [the GS loop] creates I do believe that we are putting down too little resources and time..."

First-line management interviewees established that they did not have a coherent way of engaging their production teams in the GS loop. These arguments were strengthened by the non-existence of process documentation. A couple of first-line managers described how they gathered all the operators for an afternoon in order to together create the business plan. In converse, other managers argued that they had no possibility to engage their production teams in the process due to the impact on production output. One first-line manager explained why he could not engage his production teams: “...the thought is that we should involve our teams, we have not done that yet...it has not been possible to involve the teams because we have shift teams that work on different hours...we cannot involve everyone because that would require paying overtime and supplementary allowances..." 
The consequence of not being involved was highlighted by one of the team-leaders: "It only becomes a number, the culture here is that it is really cool to measure stuff, but then nothing is really done. You measure and pile it up and then they go "bother! Let's measure this instead". Not many union workers [the blue collars] are interested in it [the performance measures]."

Questions about the culture and the support that it lends to the PMS generate diversified answers. According to the top-management a culture existed in which people did not question, challenge or improve the operations. It was a culture characterised by reactivity, something needs to be dysfunctional in order to trigger an action. In contrast, one blue collar respondent argued: “...we on the shop floor are not interested in measuring anything. We know that they [the PM] are flavours of the month. We have so much fact that it is ridiculous but no actions are taken".

Top-management interview responses revealed that the top-management team supported the BS\&GP process. However, the support of the OD process was not as established as it had been severely reduced in scope. CC2 was undergoing a transformation of the production system from functional to lean and the general manager argued that the resources were not sufficient for both. The OD process was still active in some parts of the organisation, however, the decrease in utilisation had a distinct effect on the cost savings made from, from 4, 1 to 1, 9 MUSD. Moreover, the functionality of the IT-systems was emphasised by interviewees across the organisation. Interviewees from the higher organisational levels acknowledged that the IT-systems had limitations, were inflexible in regards to data extraction and that the data quality was not always fully reliable. The production manager shared an example: “... a typical and good example of this is when the hours logged in the system are suspiciously low...after asking around you get the answer that the central finance department made a small definition error in the system..."

\subsection{Case company 3 - The unstructured meeting approach \\ 4.3.1 Structural aspect}

The accounts on how the review was executed differed widely across CC3. Further, no documentation was identified nor acknowledged by the interviewees. However, several top-management interviewees acknowledged that the approach started with a top-management meeting in which the PM and objectives were reviewed. In the review several factors would guide the decision-making (Table 4) but it was emphasised by several interviewees (general manager, finance manager, production manager) that much of the changes were dictated by the company HQ. According to the general manager it was not unconventional that CC3 were simply handed new PM and goal levels without space for questioning. Interview responses from topmanagement members underlined that the execution of the review meeting would differ from year to year. The unstructured characteristic of the process was acknowledged as burdensome by the general manager: "We need to make it [the review process] distinct... we are in a phase in which we need to type out the process I can admit that it does not work well today... I addressed all the leaders [managers] with the factory measures and goals just before December...they were however not finished until March. But that is too late, it is not functional”.

Interview responses by functional managers revealed that after the top-management had decided on their PM it was their responsibility to take the review to the next hierarchical level. It was underlined in interviews with top and second-line managers that the involvement of the organisation in the review was something that was often repeated as important. However, it was at the same time acknowledged as the most challenging part to do according to the production manager: "Involving everyone is the most difficult thing to do when working with KPI's. You really want to get everyone to feel that they can contribute...in my world, if PM are generated by the factory management [top-management] then it needs to be taken down to the local departments...bad PM will lead to bad behaviour, no one will care because no one will be able to exert influence over them [the PM]". When asked about the autonomy to select PM in the lower levels of the organisation the general manager explained: "SQD [Safety, Quality, Delivery], these are the measures that should be on the shop floor level and that is enough...this is simple and contributes to the whole. SQD... first we need to get our review process functioning and then we can look into how to give autonomy to the teams".

\subsubsection{Behavioural aspect}

Interview accounts from functional managers underline that no formal requirements on how to push the PM review to the next organisational level existed. Interview responses from the finance manager and one controller revealed that the finance function discussed and decided on the PM at a department meeting. The controller explained that this was a satisfactory way of working as the department only consisted of four members. In contrast, the logistics department had a PM review day with the whole function. The logistics manager explained why he wanted his function to work in this manner: "...I do not do this, it is the function because they are the ones that will be working with this in there group. We do this in order to create the environment that makes them feel "that this is my way, this is what we should do in our group". 
The logistic function's procedure was positively perceived by interviewees across the organisation and was referred to as a good standard by a second-line production manager. The production function, which was the most employee heavy function, deployed a contrasting procedure according to interviewees from within the function. The second-line managers would receive the PM and goal levels to be deployed with suggestions of how to cascade them down further to first-line managers, team-leaders and production-teams by their superior. Accounts from team-leaders further strengthened this notion as they were simply handed their new PM from their managers. These accounts were strengthened by the production manager: "...I believe that we use a commando-structure here, we do not really have that anchoring or cascading of the measures".

Questions regarding how well the IT-system facilitated change in PM generated different responses. Two (HR top-manager \& production second-line manager) out of the 21 interviewees were positive about the IT-system. However, the majority of the respondents felt that the IT-system inhibited their ability to measure. Several interviewees blamed the new IT-system and argued that the structures of queries that were built around the old system had now vanished without anything replacements. Some interviewees however believed that with time, the new IT-system would become more flexible and better than the old system. Other argued that once the competence of how to handle the new IT-system increased the possibilities would surpass the old system's. The interviewees' perception of the culture at CC3 was diversified. On one side of the extreme the finance manager felt that the organisation had a large quantity of PM that no one really cared about. In contrast, the HR manager argued that the leadership at the site was very ambitious about the PM and that they understood the need to have good measures over time. The answers were diversified throughout the organisation regardless of hierarchical belonging. However, several responses were consistent in regards to the reporting and control characteristics of the culture.

\subsection{Structural aspect}

\section{Cross-Case Analysis}

From a structural perspective, all three approaches revolved around the notion of top-down execution with strategy as a starting point. The top-down feature seems to be in place in order to create PM alignment across the organisation. Both the $\mathrm{CC} 1$ and $\mathrm{CC} 2$ approaches had this feature explicitly designed through the chain of execution. Even though CC3 lacks an explicit approach, the chain of execution is evident in how they managed PM change. The OD process (CC2) facilitated the alignment directly between the teams and strategic focus. Further, the input to the decision-making is similar across the case companies (Table 4). This validates the established belief that PM and strategy need to achieve alignment. Further, the approaches were executed annually/semi-annually and were thus seen as recurring activities as argued by Neely et al. (2002b), and Medori and Steeple (2000). Further, the liberty to develop PM is another common feature. CC1 and CC2 allowed their employees to develop PM if they supported the overriding organisational direction. PM autonomy seemed to be perceived as an important function for gaining the involvement. It seems that the underlying notion was that PM autonomy would amplify involvement that in turn would drive performance. Involvement of employees is underlined by Spitzer (2007) as pivotal factor.

Further, the possible relationship between the level of documentation/facilitation and the execution time needs to be highlighted. The approaches with facilitators and documentation were executed between 1-3 weeks whilst the dittos without took between 1-5 months to execute. These findings strengthen the calls for ownership of the PM change process (Kaplan and Norton, 2005; 2008) and a structured and defined approach (Meekings, 2005). Thus, if adequate resources are dedicated from the start the conditions for involving the organisation are plausibly greater. Furthermore, such a proactive stance will lead, in the long-run, to a process that requires fewer resources to execute (Neely et al., 2002a). Moreover, several researchers underlined the need of adequate IT-capabilities (Bititci et al., 2000; Wettstein and Kueng, 2002; Kennerley et al., 2003). The ITsystem was highlighted across the case studies as an influencing factor. The challenge highlighted was not being able to measure due to inflexibility. Further, fragmented IT-systems had consequences beyond inflexibility such as time for data extraction, compilation and human errors. Further, another aspect is the structure built around a given IT-system. CC3 replaced an old fragmented system with a new and integrated ditto that would enhance flexibility. However, with both competence and supporting structures erased the new system was perceived as less flexible and more problematic.

\subsection{Behavioural aspect}

Even though the role of employee involvement was underlined as sought-after and important, all three companies had problems in making it a reality. Several plausible explanations exist based on the empirical evidence. The rigid and hierarchical chain of execution might make more damage than good. It became evident at $\mathrm{CC} 2$ that the chain of execution can become a problem if not accompanied with the appropriate level of resources. The managers at the lowest levels did not get their input in time and were not cleared resources to try to involve their production teams. The OD approach deviated from the hierarchical execution and allowed each 
Performance Measurement And Management System - Inter Company Case Study Approach -

team to develop goals and PM in support of the strategic focus without any intermediaries. The OD approach of structuring the review process required less time to execute while including the whole organisation. Moreover, in relation to the chain of execution, size matters. At CC3, the finance function had no problems involving the employees. The employee-wise larger logistics function could involve most of its employees but had to work around the production planning. In contrast, the function with the highest number of employees (production), simply deployed the changes brought to them. Thus, a negative correlation seems to exist between the department size and the level of involvement. An increase in size equals an increase in needed resources, mainly time and additional labour costs. However, as illustrated at CC3, if resources are not made available the involvement will be suffocated. The need to give sufficient resources is highlighted by Spitzer (2007). Further, the challenge of employee involvement is further amplified by the lack of top-management understanding. As illustrated in $\mathrm{CC} 2$, little time was given to the lower levels. Instead, the higher management levels consumed the larger portion of the time available leaving the organisation, at best, with time constraints. As gatekeepers of organisational resources, top-management plays an important role in establishing a functional review approach. Several of the major hurdles identified regarding the involvement have their roots in management action and decision-making. The top-management needs firstly to understand the requirements of executing a PM review approach characterised by a chain of execution and secondly to make the required resources available.

However, there are other aspects of the challenges of involvement that are evident in the empirical data. The situation at CC1 illustrates that ownership and education can be two barriers of employee involvement. Once these two were given to promoted individuals they got involved. These two factors built a barrier at a CC1 which had; a defined and documented process, designated facilitators, visual aids and no resource complains (Spitzer, 2007). Thus, even though CC1 had, in contrast to the other case companies, better conditions, it was restrained by a lacklustre employee attitude towards involvement that was only dispersed through education and ownership. Top-management support is highlighted (Kennerley et al., 2003) as a factor affecting the ability to manage change in PM. The empirical data underline that respective top-management team is committed to respective review approach. However, if the commitment would be juxtaposed to the actions of respective topmanagement team a different picture would emerge. $\mathrm{CC} 2$ confined the OD process regardless of the considerable cost savings. Moreover, none of the CC2 and CC3 top-management teams did provide enough resources for execution. Top-management's actions at $\mathrm{CC} 1$ seem to be more in line with their claim of commitment. Even though their attempt to involve the organisation was postponed, their process had both a facilitator and solid structure. Moreover, Kennerley et al. (2003) underline the need of a beneficial measurement culture. Judging by both interview responses and how each approach was executed, there is evidence that none of the organisations had PM beneficial cultures in place. Even though the cultures shared this commonality, they seemed to differ in characteristics. At $\mathrm{CC} 1$, the hierarchical rigidness made it challenging to involve the employees and discussion was synonymous with informing. At $\mathrm{CC} 2$, the top-management teams and employees perceived each other to be reactive with neither willing to act on the PM. At CC3, the limitations in autonomy and liberty of action reduced PM to a reporting vehicle to be decided upon by superiors.

\section{Conclusions, Future Research, Contribution And Limitations}

Even though the case companies had different approaches in place to manage change in PM, they shared several commonalities. Commonalities were shared in the way of execution, process input and challenges in IT and culture. Furthermore, employee involvement seemed to be the biggest challenge for all three companies. From the empirics and conclusions presented in this paper, several interesting areas have emerged suitable for the future research agenda:

1. More descriptive case studies are needed that sheds further light on how PM change is managed in practice. Even though this paper has helped to bridge the knowledge gap, more research is needed.

2. How to gain organisational involvement is pivotal. This paper has elaborated over the causes but more research is needed that specifically focuses on the involvement of the employees.

3. The relationship between involving employees and driving performance ought to be investigated. As illustrated, involving the masses from an organisation of considerable size requires resources. If the involvement does not impact on the performance it would be counterproductive to have it in a review approach.

However, the findings put forward in this paper are limited as they are confined to three companies from the same company-group. More studies, both from within and outside the company-group, are needed in order to establish a solid base of empirical data for generalisation. Further, the theoretical background presented in this paper is confined to the field of PMM. Even though there are limitations to the research put forward in this paper, it helps to bridge the gap of knowledge regarding how PM change in managed in practice. This paper makes a contribution both through describing how three companies manage PM change and through elaborating on the underlying factors affecting functionality. Furthermore, the paper also provides insights for practitioners regarding the challenges faced by manufacturing units in managing change in PM. As the challenges seem to be 
similar across the case companies one implication could be to increase the cooperation and benchmarking across company-groups in order to capitalise on best practices and proven solutions.

\section{References}

[1]. Barrows, E. and Neely, A. (2012). Managing Performance in Turbulent Times - Analytics and Insights. New Jersey, USA: John Wiley and Sons Inc.

[2]. Bell, J. (1999). Introduktion till forskningsmetodik. Lund, Sweden: Studentlitteratur.

[3]. Bernolak, I. (1997). Effective measurement and successful elements of company productivity: The basis of competitiveness and world prosperity. International Journal of Production Economics, 52, pp. 203-213.

[4]. Bititci, U.S., T. Turner and Begemann, C. (2000). Dynamics of performance measurement systems. International Journal of Operations \& Production Management, 20 (6), pp. 692-704.

[5]. Bititci, U.S., Suwignjo, P. and Carrie, A.S. (2001). Strategy management through quantitative modelling of performance measurement systems. International Journal of Production Economics, 69, pp. 15-22.

[6]. Bititci, U.S., Carrie, A.S. and T. Turner. (2002). Integrated performance measurement systems: structure and dynamics. In Neely, A. (2002). Business Performance Measurement - Theory and practice. Cambridge University Press: Cambridge, UK.

[7]. Bourne, M., Wilcox, M., Neely, A. and Platts K. (2000). Designing, implementing and updating performance measurement systems. International Journal of Operations \& Production Management, 20 (7), pp. 754-771.

[8]. Bourne, M. (2008). Performance measurement: learning from the past and projecting the future. Measuring Business Excellence, 12 (4), pp. 67-72.

[9]. Cross, K.F. and Lynch, R.L. (1992). For good measure. Certified Management Accountants (CMA) Magazine, 66 (3), pp. $20-24$.

[10]. Denscombe, M. (2000). Forskningshandboken - för småskaliga forskningsprojekt inom samhällsvetenskap [In Swedish]. Lund, Sweden: Studentlitteratur.

[11]. Eisenhardt, K.M. (1989). Building theories from case study research. Academy of Management Review, 14 (4), pp. 532-550.

[12]. Farris, J., Van Aken, M.E., Letens, G., Chearksul, P. and Coleman, G.D. (2011). Improving the performance review process - a structured approach and case application. International Journal of Operations \& Production Management, 31 (4), pp. $376-404$.

[13]. Hass, S., Burnaby, P., and Bierstaker, J.L. (2005). The use of performance measures as an integral part of an entity's strategic plan. Managerial Auditing Journal, 20 (2), pp. 179-186.

[14]. Kaplan, R.S. and Norton, D.P. (1992). The balanced scorecard - measures that drive performance. Harvard Business Review, January-February, pp. 71-79.

[15]. Kaplan R.S. and Norton D.P. (2001). The strategy-focused organization. Massachusetts, USA: Harvard Business School Press.

[16]. Kaplan R.S. and Norton D.P. (2005). The office of strategy management. Harvard Business Review, October.

[17]. Kaplan R.S. and Norton D.P. (2008). The office of strategy management: emerging roles and responsibilities. Balanced scorecard report, 10 (4), pp. 1-7.

[18]. Kennerley, M. and Neely, A. (2002). A framework of the factors affecting the evolution of performance measurement systems. International Journal of Operations \& Production Management, 22 (11), pp. 1222-1245.

[19]. Kennerley, M. and Neely, A. (2003). Measuring performance in a changing business environment. International Journal of Operations \& Production Management, 23 (2), pp. 213-229.

[20]. Kennerley, M., Neely, A. and Adams, C. (2003). Survival of the fittest: measuring performance in a changing business environment. Measuring Business Excellence, 7 (4), pp. 37-43.

[21]. Lantz, A. (1993). Intervjumetodik [In Swedish]. Lund, Sweden: Studentlitteratur.

[22]. Likierman, A. (2009). The five traps of performance measurement. Harvard Business Review, October, pp. 96-101.

[23]. Lima, E.P., Gouvea Costa, S.E. and Angelis, J.J. (2009). Strategic performance measurement systems: a discussion about their roles. Measuring Business Excellence, 13 (3), pp. 39-48.

[24]. McAdam, R. and Bailie, B. (2002). Business performance measures and alignment impact on strategy - the role of business improvement models. International Journal of Operations \& Production Management, 22 (9), pp. 976-996.

[25]. Medori, D. and Steeple, D.S. (2000). A framework for auditing and enhancing performance measurement systems. International Journal of Operations \& Production Management, 20 (5), pp. 520-533.

[26]. Meekings A. (2005). Effective review meetings: The counter-intuitive key to successful performance measurement. International Journal of Productivity and Performance Management, Vol. 54 No. 3, pp. 212-220.

[27]. Merriam, S.B. (1994). Fallstudien som forskningsmetod. Lund, Sweden: Studentlitteratur.

[28]. Miles, M.B, and Huberman, A.M. (1994). Qualitative Data Analysis, 2nd Edition. California, USA: Sage Publication Inc.

[29]. Neely, A., Mills, J., Platts, K., Gregory M. and Richards, H. (1996). Performance measurement system design: Should process based approaches be adopted? International Journal of Production Economics, 46 (47), pp. 423-431.

[30]. Neely, A., Adams, C. and Kennerley, M. (2002a). The Performance Prism. Harlow, UK: Prentice Hall.

[31]. Neely, A., Bourne, M., Mills, J., Platts, K. and Richards, H. (2002b). Getting the measure out of your business. Cambridge, UK: Cambridge University Press.

[32]. Neely, A. (1999). The performance measurement revolution: why now and what next? International Journal of Operations \& Production Management, 19 (2), pp. 205-228.

[33]. Int. Journal of Business Science and Applied Management / Business-and-Management.org

[34]. 66

[35]. Paranjape, B., Rossiter B. and Pantano, V. (2006). Insights from the Balanced Scorecard: Performance measurement systems: successes, failures and future - a review. Measuring Business Excellence, 10 (3), pp. 4-14.

[36]. Salloum, M. and Wiktorsson, M. (2011). Dynamic abilities in performance measurement system: a case study on practice and strategies. Proceedings of the 18th International Annual EurOMA Conference, Cambridge, UK.

[37]. Searcy, C. (2011). Updating corporate sustainability performance measurement systems. Measuring Business Excellence, 15 (2), pp. 44-56.

[38]. Simons, R. (1995). Levers of Control. Massachusetts, USA: Harvard Business School Press.

[39]. Slack, N., Chambers, S. and Johnston, R. (2004). Operations Management, 4th edition. Harlow, UK: Pearson Education.

[40]. Silverman, D. (2010). Doing Qualitative Research, 3rd edition. London, UK: Sage Publications Inc.

[41]. Spitzer, D.R. (2007). Transforming Performance Measurement: rethinking the way we measure and drive organizational success. New York, USA: AMACOM.

[42]. Tangen, S. (2005). Analysing the requirements of performance measurement systems. Measuring Business Excellence, 9 (4), pp. 46-54. 
[43]. Tapinos, E., Dyson, R.G. and Meadows, M. (2005). The impact of performance measurement in strategic planning. International Journal of Productivity and Performance Management, 54 (5/6), pp. 370-382.

[44]. Waggoner, D., Neely, A.D. and Kennerley, M.P. (1999). The forces that shape organisational performance measurement systems: An interdisciplinary review. International Journal of Production Economics, 60 (61), pp. 53-60.

[45]. Wettstein, T. and Kueng, P. (2002). A Maturity Model for Performance Measurement Systems. In Brebbia, C. and Pascola, P. (2002). Management Information Systems - incorporating GIS and Remote Sensing. Southampton, UK: WIT Press.

[46]. Yin R.K. (1994). Case study research: Design and methods, 2nd edition. California, USA: Sage Publications Inc 